\title{
Blogs: De Diários Pessoais a Comunidades Virtuais de Escritores/leitores
}

\author{
Blogs: From Personal Diaries to Virtual \\ Communities of Writers/readers
}

Blogs: De Diarios Personales a

Comunidades Virtuales de Escritores/lectores

Flavia Di Luccio \&

Ana Maria Nicolaci-

da-Costa

Pontifícia

Universidade Católica

do Rio de Janeiro

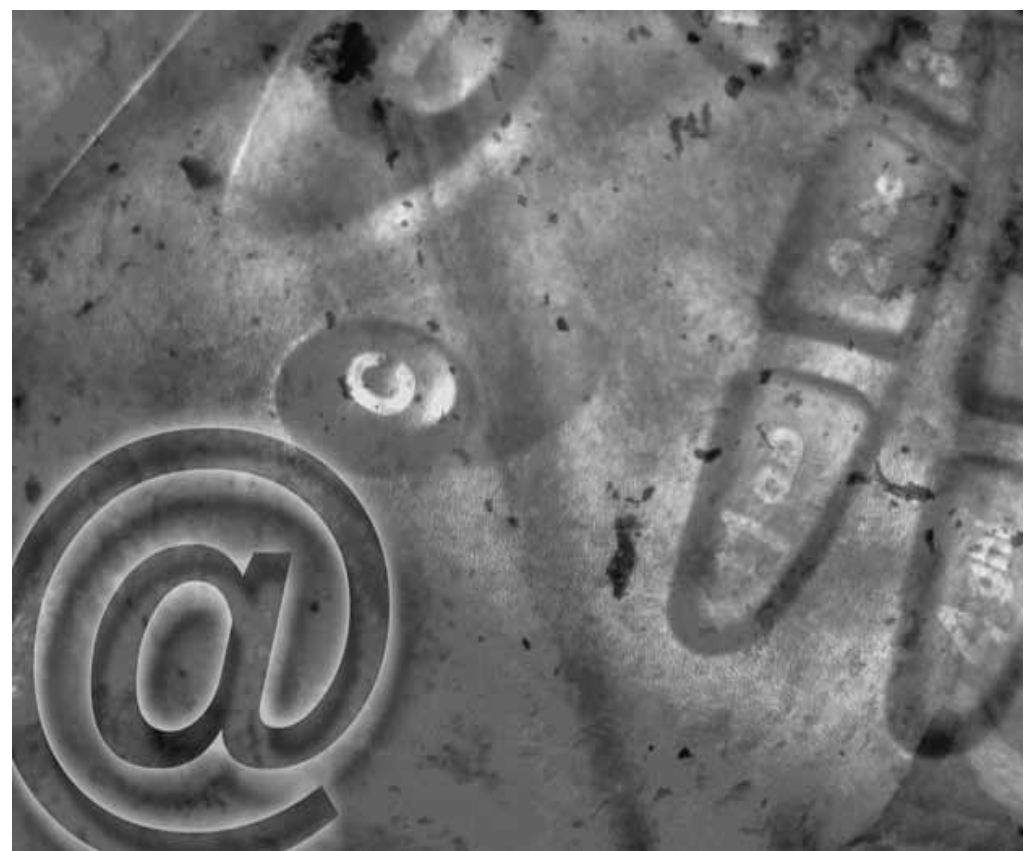


Resumo: Novos suportes de textos geram novas formas de escrever e ler. Ao longo da História, três grandes revoluções textuais foram produzidas pelas invenções do códice, da imprensa e da rede internacional de computadores. Nesse último caso, o suporte textual passou a ser a tela do computador, que, conectada às telas de outros computadores, incorporou várias características da escrita on-line, inclusive sua interatividade. Esse espaço textual interconectado pode ser subdividido em inúmeros outros. Um deles é o dos blogs. Inicialmente dedicados predominantemente ao diarismo, seu uso foi se diversificando e dando lugar a outros tipos de blog (jornalísticos, humorísticos, literários, etc). Para investigar como escritores e leitores estão usando esse novo espaço textual e seus recursos, foram realizadas entrevistas abertas com escritores de blogs brasileiros. A análise de seus depoimentos revelou que, ao mesmo tempo em que escrevem seus blogs, todos leem regularmente outros blogs e interagem com os autores destes. Como resultado, é formada uma comunidade de escritores/leitores de blogs com grande potencial de integração, contestação e formação de opinião pública.

Palavras-chave: Blogs. Comunidades virtuais. Escritores. Leitores.

\begin{abstract}
New textual supports generate new forms of writing and reading. Historically, three great textual revolutions were launched by the inventions of the codex, the press and the international computer net. In the last case, the textual support became the computer screen, which, connected to the screens of other computers, incorporated several characteristics of on-line writing, including its interactivity. This interconnected textual space can be divided into several others. One of them is that of the blogs. Initially dedicated predominantly to the writing of "virtual diaries", the diversification of its use produced other types of blogs (journalistic, humoristic, literary, etc.). In order to investigate how writers and readers are using this new textual space and its tools, open interviews with Brazilian blog writers were carried out. The analysis of their replies revealed that, at the same time that they write their blogs, all of them regularly read other blogs and interact with their writers. As a result, a community of blog writers/readers is formed, which reveals a strong potential for integration, resistance and public opinion making.
\end{abstract}

Keywords: Blogs. Virtual communities. Writers. Readers.

Resumen: Nuevos soportes de textos generan nuevas formas de escribir y leer. A lo largo de la Historia, tres grandes revoluciones textuales fueron producidas por las invenciones del códice, de la prensa y de la red internacional de computadoras. En ese último caso, el soporte textual pasó a ser la pantalla de la computadora, que, conectada a las pantallas de otras computadoras, incorporó varias características de la escritura en-línea, incluso su interactividad. Ese espacio textual interconectado puede ser subdividido en muchos otros. De ellos es el de los blogs. Inicialmente dedicados predominantemente al diarismo, su uso fue se diversificando y dando lugar a otros tipos de blog (periodísticos, humorísticos, literarios, etc). Para investigar como escritores y lectores están usando ese nuevo espacio textual y sus recursos, fueron realizadas entrevistas abiertas con escritores de blogs brasileños. El análisis de su declaraciones reveló que, al mismo tiempo en el que escriben sus blogs, todos leen regularmente otros blogs e interactúan con los autores de éstos. Como resultado, es formada una comunidad de escritores/lectores de blogs con gran potencial de integración, negación y formación de opinión pública.

Palabras clave: Blogs. Comunidades virtuales. Escritores. Lectores.

Tomadas isoladamente, as telas dos computadores são hoje revolucionários espaços multimídia, nos quais podemos escrever ou ler textos, expor ou ver fotos e outros tipos de imagem, ouvir arquivos de áudio, assistir a vídeos, etc. As telas dos computadores operam também uma transformação radical em uma área que, ao longo dos últimos séculos, se tornou central na nossa experiência cotidiana: a da escrita/ leitura. É sobre esta última que vamos nos deter neste artigo. Nosso objetivo é o de concentrarmos a atenção nas telas dos computadores como novo espaço de inserção de textos - ou seja, um novo suporte textual - que introduz alterações radicais nos nossos hábitos de escrever e ler.

Se uma tela já constitui um suporte textual revolucionário, o que podemos dizer a respeito do suporte que é gerado quando as telas dos computadores mundiais são potencialmente interconectadas via internet? É claro que as características revolucionárias das telas individuais são grandemente potencializadas na medida em que é gerado 
Chartier (1998, 1999, 2002, 2003) mostra que a escrita pode ser dividida em quatro grandes períodos separados por três grandes revoluções nos suportes textuais disponíveis. ainda outro espaço de inserção de textos - de amplitude antes impensável - que incorpora as inéditas características interativas da rede internacional de computadores. Esse novo espaço textual interconectado, no entanto, não é único nem tem características homogêneas. Pode ser subdividido em inúmeros outros, com atributos distintos, nos quais se inserem diferentes formas de escrita que têm diferentes propósitos. Alguns exemplos são os espaços do e-mail, das trocas instantâneas de mensagem, dos diversos ambientes de interação e relacionamento (como, por exemplo, o Orkut ou o Par Perfeito), dos diversos tipos de site (como os sites de empresas ou os sites jornalísticos) e muitos mais. O blog, cujas formas de uso temos por objetivo analisar, é um exemplo bem-sucedido desses muitos espaços gerados pelas telas dos computadores interconectados como suporte textual. As especificidades e as características revolucionárias desse novo suporte bem como aquelas dos blogs podem ser mais bem apreciadas se inseridas no contexto da evolução da escrita.

\section{Uma breve incursão pela evolução da escrita}

A história da evolução da escrita no mundo ocidental está diretamente ligada às mudanças sofridas pelos suportes textuais através dos tempos. Novos suportes de textos originaram novas formas de escrever, de ler e de escritores e leitores se relacionarem com o texto produzido ou lido e também entre si.

Chartier (1998, 1999, 2002, 2003) mostra que a escrita pode ser dividida em quatro grandes períodos separados por três grandes revoluções nos suportes textuais disponíveis.

A primeira dessas revoluções aconteceu entre os séculos II e IV da era cristã, e foi gerada pela substituição do rolo de papiro ou pergaminho pelo códice manuscrito. O rolo era um suporte grande e pesado, tão difícil de ser manipulado (sua manipulação requeria o uso de ambas as mãos) que fazia com que o escritor necessitasse de um auxiliar: o escriba. O escritor ditava seus textos para o escriba de modo a poder ficar livre para manusear outras obras, fazer anotações, etc. Já os leitores tinham que segurar o rolo com as duas mãos durante a leitura e não podiam transportálo facilmente. Dessa forma, a leitura ficava restrita aos gabinetes e às salas de leitura, nas quais havia grandes mesas ou escrivaninhas que eram utilizadas para apoiar o suporte.

A invenção do códice manuscrito mudou radicalmente esse quadro. Assim como o rolo, o códice era composto por folhas de papiro. A diferença é que tais folhas eram dobradas um certo número de vezes e costuradas, assemelhando-se muito ao formato do livro atual. A considerável diminuição do tamanho e do peso do novo suporte textual permitiu que escritores e leitores ganhassem mais liberdade. O escritor de códice pôde dispensar o escriba. Podia ler enquanto escrevia, comparar duas ou mais obras abertas e, principalmente, localizar trechos a partir da paginação e da indexação que foram então introduzidas. Para os leitores, tornou-se possível transportar o novo suporte textual, que podia ser lido em qualquer lugar. Os leitores podiam também fazer anotações durante a leitura, pois era possível segurar o suporte com uma das mãos apenas.

A segunda revolução nos suportes textuais teve início quando, no século XV, Gutenberg inventou a imprensa. Chartier (1999) tem uma posição interessante no que diz respeito à importância desta. Embora reconheça as grandes mudanças por ela provocadas (principalmente no que concerne 
A era da imprensa foi marcada pela proliferação de textos e, em consequência, pelo aumento considerável do número daqueles que os liam (Chartier, 1999). à democratização do acesso aos livros), ele afirma que as transformações dela decorrentes não foram tão radicais para os escritores e leitores quanto as da primeira revolução textual (e, principalmente, como veremos adiante, as da terceira), isso porque o formato e a disposição dos textos nas páginas do códice impresso e do códice manuscrito são os mesmos.

Apesar disso, a realidade pós-Gutenberg foi repleta de mudanças, tanto para escritores quanto para leitores. O escritor pósGutenberg passou a produzir seus textos individualmente, e, posteriormente, a enviá-los para receberem o tratamento de outros profissionais. Uma vez escritos, os textos eram passados para os tipógrafos, que eram responsáveis pelas escolhas gráficas e ortográficas dos textos. A seguir, eram encaminhados para os impressores, que decidiam a composição tipográfica das páginas. Uma vez terminado o trabalho destes, seguiam para os corretores, que buscavam garantir a correção das obras impressas, preparavam o manuscrito que servia de original para a composição impressa, corrigiam as provas e faziam a revisão durante a tiragem. Após todas essas etapas, o material impresso, o livro, era encaminhado ao livreiro, que era responsável por sua comercialização. Junto a todos esses profissionais da escrita, estava o editor, um empreendedor do texto, que desempenhava um papel importante na mediação cultural e inventava fórmulas capazes de associar repertório textual e capacidade produtiva.

A era da imprensa foi marcada pela proliferação de textos e, em consequência, pelo aumento considerável do número daqueles que os liam (Chartier, 1999). Os cada vez mais numerosos leitores tornaram-se também mais livres e móveis, pois as novas técnicas de impressão permitiam a confecção de volumes menores e mais leves. Mesmo assim, uma característica das eras anteriores se mantinha: o leitor limitava-se a interagir imaginariamente com o texto que lia, nele não podendo introduzir alterações (a não ser sublinhando ou escrevendo nas margens) e não tendo acesso direto (e fácil) aos seus autores.

A terceira revolução da escrita é bem recente. Teve início com a difusão dos computadores, que fizeram de suas telas, principalmente quando interconectadas, um novo suporte de textos. Para Chartier (2003), essa última revolução é a mais radical de todas, porque a tela como suporte textual mudou radicalmente a forma de lermos e fez surgir escritores e leitores também radicalmente diferentes dos anteriores, possibilitando inclusive o inédito contato de uns com os outros no mesmo suporte textual.

Se a tela do computador se tornou um suporte textual, podemos compreender que, ao interconectar as telas dos computadores mundiais, a internet gerou um suporte textual de dimensões planetárias. Qualquer pessoa que disponha de um computador e tenha acesso à internet passa a poder publicar qualquer tipo de texto sem restrições e sem interferências de escribas, tipógrafos, impressores, corretores ou editores. Na tela conectada à internet, o escritor se tornou livre para desenvolver todo o processo de confecção e de divulgação de um texto. Além disso, diferentemente do que acontecia na era do rolo, do códice e da imprensa, o escritor de hipertextos - os textos eletrônicos - pôde abandonar a clássica lógica linear e dedutiva e escrever textos que (por meio de links) permitem o deslocamento da leitura para outros textos. Os mesmos links e a mesma lógica permitem também o diálogo com os leitores e com outros autores. 
A nova estruturação do texto on-line também deu muito mais liberdade aos leitores. $\mathrm{Na}$ tela, desapareceram as capas, páginas, capítulos, índices, sumários, notas, etc. Em contrapartida, apareceram outros recursos - a exemplo dos links - que colocam os leitores diante de uma textualidade móvel e infinita. A leitura tornou-se não linear, buscando a compreensão do texto como um todo a partir de palavras-chave, links ou fragmentos textuais. Por isso mesmo, passou a ser sempre singular, na medida em que sua trajetória depende das opções do leitor.

\section{Blog: um espaço textual revolucionário}

$\mathrm{Na}$ internet, grande parte da informação/ comunicação circula por escrito. São, portanto, muitos os espaços textuais que nela existem com os mais diferentes propósitos. $\mathrm{O}$ weblog, ou blog, é um desses muitos espaços. É, no entanto, um espaço que dá concretude às novas possibilidades textuais geradas pela conexão em rede dos computadores mundiais. Talvez exatamente por esse motivo, o blog venha se tornando cada vez mais popular e poderoso.

Lemos (2002) nos leva ao início do mundo dos blogs. Ele nos diz que o termo weblog, posteriormente reduzido para blog, foi criado por John Barger, editor do site Robot Wisdom, em 1997. Um weblog é uma página da web onde um weblogger, também chamado de blogger (blogueiro), logs (registra por escrito como em um diário de bordo) outras páginas da web e textos selecionados.

Os principais recursos utilizados nos blogs são os posts, textos que podem ser alterados, apagados, atualizados, etc. com a frequência que o autor desejar. Os posts podem incluir links para outras páginas da web ou para outros blogs. Novos posts são acrescentados no topo da página. Abaixo ou acima do post, podemos encontrar a data e a hora de sua publicação. Dessa forma, os leitores podem acompanhar o blog lendo as publicações em ordem cronologicamente inversa. Outro recurso quase sempre presente nos blogs é a caixa de diálogos, por meio da qual os leitores podem enviar seus comentários para o escritor.

A popularização dos blogs foi muito rápida. Em janeiro de 2008, o site de busca Technorati (http://technorati.com/about/), especializado em registrar os blogs existentes na internet, já registrava mais de 112 milhões de usuários ao redor do mundo. Então, esse mesmo site também afirmava que 120 mil novos blogs apareciam na rede todos os dias.

Talvez por conta de sua associação com os diários de bordo aludidos em seu nome, nos primeiros tempos, eles eram principalmente usados como um espaço para escrever sobre si mesmo (Prange, 2002; Komesu, 2005; Marcuschi \& Xavier, 2005), e rapidamente se tornaram conhecidos como diários virtuais. Um exemplo é o blog Just Lia (http://www. justlia.com.br/), no qual pode ser encontrado um diário que tem início no ano 2000.

No Brasil, os blogs começaram a se difundir entre os anos 2000 e 2001. Embora não disponhamos de números, sabemos que, entre nós, sua disseminação foi tão veloz e contínua quanto no resto do mundo. Essa disseminação, por sua vez, abriu espaço para o surgimento de blogs dedicados a outros gêneros de escrita que não o inicial do diarismo.

\section{Alguns outros gêneros de blogs}

Atualmente, os blogs são usados com múltiplas finalidades. Uma delas é a do jornalismo on-line (Recuero, 2003a, 2003b; Schittine, 
2004; Silva, 2003). Nesse tipo de blog, um grande atrativo é o fato de os blogueiros poderem publicar uma notícia com ampla liberdade e sem a preocupação com editores, críticos, prazos ou espaço para publicação de seus textos. É desnecessário dizer que isso representa uma quebra de paradigmas no jornalismo contemporâneo (Recuero, 2003b) e afeta tanto o jornalismo on-line quanto o convencional, off-line. Segue-se um exemplo: no final de 2002, um arquiteto iraquiano, que usava o pseudônimo Salam Pax, decidiu narrar em seu blog Where is Raed? (http://dear_raed.blogspot.com/) o dia a dia da guerra no Iraque. No início, o blog era apenas o diário das experiências cotidianas de um homem em um país em guerra. Rapidamente, no entanto, ganhou popularidade e passou a ser uma fonte de informação para a mídia e para as pessoas do mundo inteiro. Certamente, após os relatos dos ataques ao Iraque feitos pelo blogueiro iraquiano, as coberturas jornalísticas nunca mais foram as mesmas. A partir de então, os blogueiros/jornalistas passaram a ocupar um espaço relevante na mídia mundial.

No Brasil, temos um bom exemplo disso. O popular blog político do jornalista Ricardo Noblat, inicialmente desvinculado de qualquer instituição jornalística, conquistou inúmeros leitores e virou referência, mostrando que é possível fazer uma cobertura política digna de confiança em um blog. O Blog do Noblat se popularizou tanto que o jornalista foi contratado pelo jornal O Globo, e atualmente escreve em um blog dentro do site do jornal (http://www.oglobo.globo.com/ pais/noblat).

Além dos blogs com foco em assuntos políticos (blogs políticos), podemos observar a progressiva disseminação de outro tipo de blog jornalístico: aquele que Silva (2003) chama de weblog livre e que preferimos chamar de blogzine, por analogia a magazine (revista). Tal como em uma revista, nesse tipo de blog, podemos encontrar matérias jornalísticas, esportivas, econômicas, informações culturais, conselhos de beleza, moda, decoração, notícias do País e do mundo, etc. No entanto, diferentemente do que acontece em uma revista impressa ou on-line, no blogzine, o jornalista/blogueiro tem a liberdade de escolher o(s) assunto(s), a linguagem e a extensão dos textos publicados. Além disso, a partir da caixa de diálogos para comentários, pode ser mantido um debate entre jornalistas/ blogueiros e leitores. Um bom exemplo de um blogzine é o blog Querido Leitor (www. queridoleitor.zip.net), da jornalista/blogueira Rosana Hermann.

Somando-se aos diários virtuais e aos blogs jornalísticos, ainda outro tipo de blog vem se difundindo rapidamente na rede: o blog literário. Nesse tipo de blog, assim como no blogzine, os mais variados assuntos são abordados. O que marca a diferença entre um gênero e outro é o fato de o blog literário ser visto por seus autores como um espaço de criação, experimentação, publicação e divulgação de seus próprios textos. A mídia, impressa e on-line, tem reconhecido o mérito de vários desses blogs e divulgado livros que neles tiveram origem. O sucesso de alguns desses autores vem sendo tão grande a ponto de serem chamados de novos escritores por jornalistas, escritores ou críticos literários. $\mathrm{O}$ blog do escritor Fabrício Carpinejar, criado em 2003, (http://www.fabriciocarpinejar.blogger. com.br/) ilustra bem o que vem a ser um blog literário de sucesso.

Jornalísticos, esportivos, literários, de guerra, de humor, de fofocas, de economia, de política ou corporativos, o fato é que os blogs se difundiram, divulgaram o trabalho 
de seus autores (os tornando muito famosos) e se transformaram em importantes espaços de escrita e leitura de textos dos mais variados gêneros, espaços esses que têm em comum a possibilidade de comunicação entre leitores e escritores. Tudo isso é muito novo, e, exatamente por esse motivo, na linha do que vimos fazendo ao longo da última década (Nicolaci-da-Costa, 2006, 2007), requer que sejam realizadas pesquisas exploratórias que deem início à produção de conhecimento sobre os impactos gerados pela terceira revolução da escrita. Entender o que leva pessoas comuns a se tornarem escritoras (e/ou leitoras) de blogs, como elas administram a sua produção, como elas fazem uso da interatividade nos pareceu um bom começo. Somente desse modo poderemos apreender os processos e dinâmicas por meio dos quais esse novo espaço textual tornou tão popular o ato de escrever... Para tanto, foi realizada a pesquisa (Di Luccio, 2005) cuja apresentação se segue.

\section{A pesquisa}

Com a finalidade de obter respostas relevantes para esses questionamentos, optamos por dar voz a escritores de blogs. Logo percebemos, porém, que esses escritores também eram leitores assíduos de outros blogs, aos quais faziam menção, para os quais colocavam links e dos quais chegavam mesmo a incorporar trechos em seus próprios blogs. Em outras palavras, eram escritores/leitores. Assim sendo, toda a pesquisa foi realizada com escritores/leitores de blogs brasileiros - de qualquer tipo - que eram atualizados frequente e regularmente.

\section{Metodologia}

\section{Participantes}

Para selecionar os participantes, foram estabelecidos alguns critérios de recrutamento:

(a) todos os participantes deveriam ser brasileiros, porque um grupo composto por brasileiros e estrangeiros poderia resultar em uma heterogeneidade inadequada para este estudo; (b) todos deveriam ser adultos (na realidade, como veremos abaixo, suas idades variaram entre 27 e 42 anos); (c) para que já tivessem pleno domínio do espaço e ferramentas, todos deveriam ter seus blogs há no mínimo um ano; (d) todos deveriam manter seus blogs atualizados, renovando seus posts e imagens ao menos semanalmente; (e) os blogs de todos os participantes deveriam apresentar a seção de comentários, de modo a tornar possível a interação entre leitores e autores e também entre leitores e leitores. Não foram feitas quaisquer restrições quanto a sexo ou profissão nem foi selecionado nenhum gênero específico de blog.

Com base nesses critérios, foi feito o recrutamento dos participantes da pesquisa. Para tanto, foram enviados e-mails individuais a 20 autores de blogs, convidando-os a participar da pesquisa. Recebemos respostas de 16 autores, mas somente 9 deles -6 homens e 3 mulheres - de fato nos concederam entrevistas. Caso fosse necessário, estávamos dispostas a repetir o convite a outros autores, mas tal necessidade não se materializou, como será discutido na seção de resultados.

Era o seguinte o perfil dos nossos participantes: um tinha 30 anos e trabalhava como bancário e webwriter (embora fosse formado em jornalismo); dois tinham 37 anos, sendo um funcionário público (oficial de justiça) com curso superior incompleto e o outro, bancário e formado em Direito. Outros dois eram jornalistas: um deles tinha 27 anos e a outra 42 (esta tinha pós-graduação em Arte e Filosofia). Entre os participantes, havia também dois advogados, ambos com 27 anos, sendo que uma tinha pós-graduação em Direito do consumidor e o outro em Direito 
empresarial. O oitavo entrevistado tinha 28 anos, era formado em gestão de negócios internacionais e editor-chefe de um portal. A nona e última entrevistada tinha 40 anos, era diretora de conteúdo web (não tinha formação superior). Dos 9 entrevistados, 3 eram do Rio de Janeiro (RJ), 4, de São Paulo (SP), 1, de Juiz de Fora (MG) e 1, de Brasília (DF).

A todos os entrevistados foram atribuídos nomes fictícios para a preservação de seu anonimato. Tal preservação, no entanto, não foi considerada relevante pelos participantes desta pesquisa, já que, quando fizemos menção ao anonimato, a maioria disse que estar constantemente exposto fazia parte da rotina de um escritor de blog.

\section{Coleta de dados}

Os dados foram coletados por meio de entrevistas individuais de cerca de uma hora e meia de duração cada. Todas as entrevistas foram realizadas pela internet (Nicolaci-daCosta, Romão-Dias, \& Di Luccio, 2009), e os programas escolhidos pelos entrevistados foram o ICQ (I seek you) ou MSN Messenger. Ambos são programas de trocas instantâneas de mensagens que permitem bate-papos on-line e em tempo real, utilizando uma linguagem simplificada e rápida. A realização das entrevistas via internet se deu devido à facilidade do acesso aos entrevistados. De fato, os primeiros contatos com os participantes já haviam sido feitos on-line, por meio da seção de comentários de seus blogs ou por e-mails individuais. Além disso, o uso do ICQ e do MSN permitiu a realização de entrevistas com participantes que moravam em cidades distantes do Rio de Janeiro, local no qual se encontravam as entrevistadoras. Todos os entrevistados dominavam muito bem as ferramentas desses programas, e demonstraram estar muito à vontade nas entrevistas virtuais.

Tanto a construção do roteiro como as diretrizes para sua aplicação seguiram os princípios do método de explicitação do discurso subjacente (MEDS), tal como descritos por Nicolaci-da-Costa $(2007,2009)$. Assim sendo, como instrumento de coleta de dados, foi usado um roteiro estruturado composto de itens a partir dos quais deveriam ser formuladas as perguntas durante a própria entrevista. O uso de itens e não de perguntas prontas visava a preservar as características de conversas informais (perguntas prontas tendem a soar artificiais). Também de acordo com as diretrizes do MEDS, esse roteiro estruturado era aplicado de forma flexível durante as entrevistas, podendo a ordem dos itens ser alterada de modo a manter o fluxo de associações do entrevistado e perguntas de aprofundamento podendo ser introduzidas sempre que necessário (do tipo "por que?", "como assim?", "dá para explicar melhor?").

O roteiro era dividido em duas partes. A primeira era composta de perguntas objetivas sobre os participantes, tais como: idade, escolaridade, profissão, ocupação, etc. Já a segunda parte era composta por 11 itens/perguntas de cunho mais subjetivo, que abordavam os seguintes tópicos: (1) a decisão de criar um blog, (2) a frequência de atualização dos posts, (3) a importância dos comentários recebidos, (4) a reação às críticas feitas nos comentários, (5) a falta de comentários, (6) o que o (a) entrevistado(a) achava atraente em um blog como leitor(a), (7) o que achava que atraía seus leitores, (8) como era o(a) entrevistado(a) no blog, (9) como era o(a) entrevistado(a) fora dele, (10) o papel do blog na vida do entrevistado(a) e (11) as mudanças que ocorreram em sua vida e nele(a) próprio(a) após a criação do blog. 


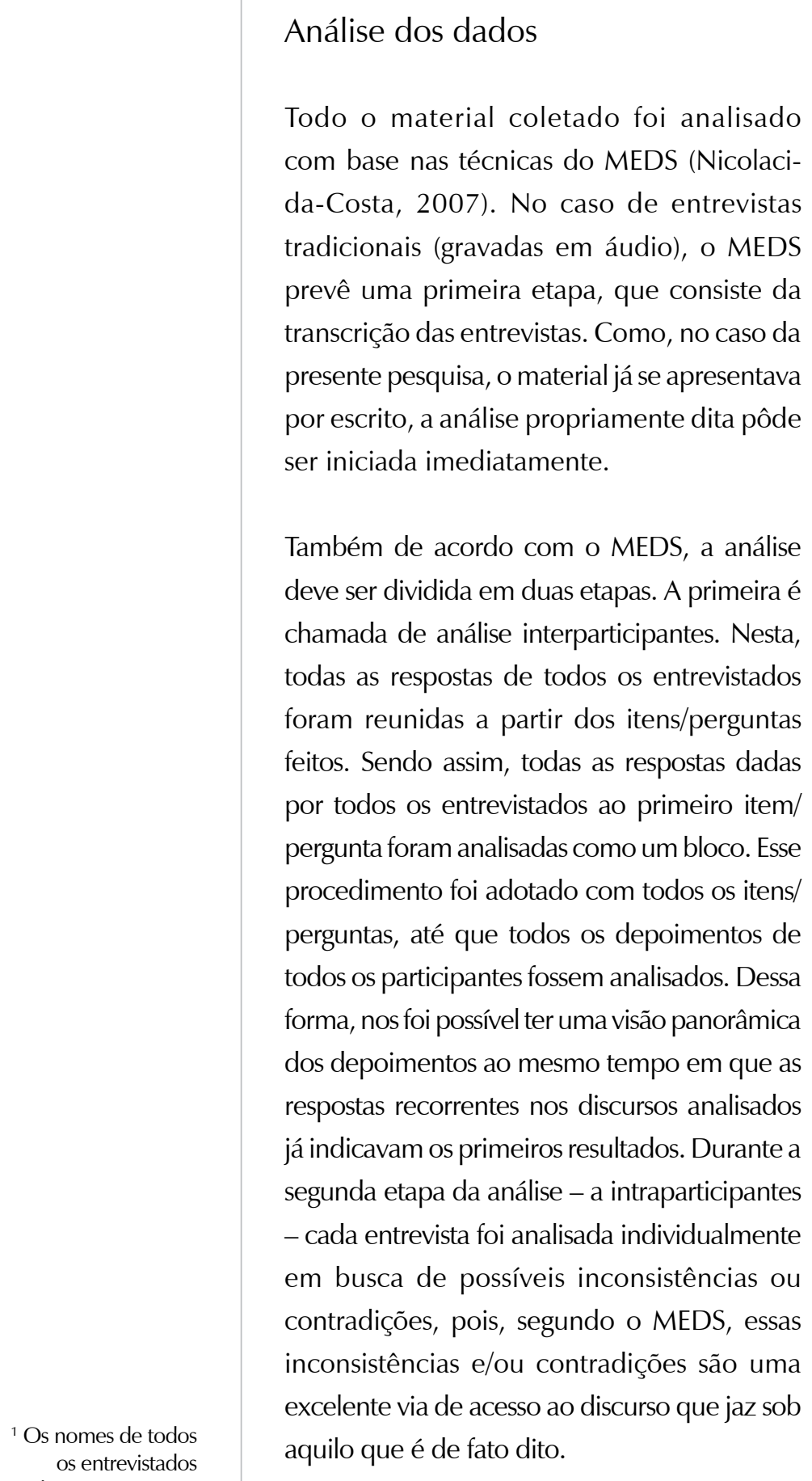

desta pesquisa são fictícios, e todos os depoimentos apresentados neste estudo foram reproduzidos com todas as suas características linguísticas originais; dessa forma, erros de digitação,

equívocos linguísticos e abreviações são frequentes.

\section{Resultados}

Como afirmamos anteriormente, estávamos receosas de que o número de autores de blogs que haviam aceitado participar da pesquisa fosse pequeno demais para que pudéssemos chegar a conclusões bem fundamentadas. Isso, no entanto, não ocorreu, na medida em que os discursos de nossos entrevistados rapidamente atingiram aquele que Bertaux (1980) chama de ponto de saturação, ou seja, o ponto em que, após um certo número de entrevistas, o entrevistador começa a ouvir, de novos entrevistados, relatos muito semelhantes àqueles que já ouviu, havendo uma rarefação de informações novas (Seidman, 1998; Nicolacida-Costa, 2007). Os resultados que se seguem foram, portanto, baseados nos depoimentos dos nove entrevistados mencionados acima.

\section{Escritores de blogs são leitores de blogs}

Como mencionado anteriormente, a leitura de vários blogs que antecedeu a pesquisa já nos havia fornecido indícios de que os escritores de blogs são também leitores de outros blogs. Tal constatação ficou ainda mais evidente quando analisados os depoimentos coletados. Então, pudemos de fato perceber que, nos blogs, escritores e leitores se misturam e se fundem.

Na realidade, todos os escritores de blogs entrevistados revelaram ser também leitores de blogs. Para começar, antes de se tornarem escritores, os entrevistados, em sua maioria, eram leitores de blogs que ficaram encantados com os recursos do novo espaço textual e decidiram criar seu próprio blog. Seguem-se dois exemplos.

Maíra ${ }^{1}$ afirma:
Achei, assim à primeira vista, uma ferramenta
incrível, com grandes possibilidades...
porque eu dei a sorte de cair em vários
blogs de escritores ou pessoas que gostavam
muito de literatura, como eu, e me senti
em casa, exceto pelo fato de que eu era
a única que ainda não tinha blog... antes
disso, eu achava que eu era a única que
ainda gostava de ler e de escrever. (Maíra,
27 anos, advogada) 
Júlio também começou sua jornada como escritor de blogs lendo outros blogs. Chega a admitir que, quando resolveu fazer seu próprio blog, escolheu ter, como seus primeiros leitores, os escritores que admirava e lia muito. Para tornar isso possível, fez uso dos recursos da rede e enviou-lhes o endereço de seu blog. Diz: "Escrevi durante algumas semanas só para mim, para dominar o sistema... depois mandei o endereço para as tais pessoas que admiro: João, Margarete, Fabiana. E a recepção foi além do que eu imaginava..." (Júlio, 37 anos, bancário).

Para os entrevistados, a leitura de outros blogs, contudo, não ficou confinada ao início. Eles continuam a ler, ou, em suas próprias palavras, a visitar/frequentar os blogs de outros escritores que apreciam.

Júlio, por exemplo, é um escritor que visita outros blogs com frequência, por isso, sabe o que esperar dessas visitas. Diz: "Cada blog tem um estilo. Sabemos o que vamos encontrar após algumas visitas" (Júlio, 37 anos, bancário).

Já Eros diz conhecer outros blogs que a visitam. Ela própria revela também fazer esse tipo de visita ao declarar que: "tem MUITO blog BOM mesmo. com conteúdos maravilhosos. em alguns eu me perco pelos arquivos porque não quero parar de ler..." (Eros, 40 anos, diretora de conteúdo web).

Outros entrevistados não se referem a visitas, mas também demonstram frequentar outros blogs. Fox é um deles, pois, em seu próprio blog, linka (coloca links) vários outros dos quais gosta. Afirma que: " $A$ lista de blogs que linko... dá uma boa ideia do que eu gosto (como leitor): lá há blogs que falam da vida pessoal de seus autores..., blogs literários..., de fotografia... ou de charges..." (Fox, 30 anos, bancário e webwriter).

Eros nos fornece algumas pistas adicionais. Em sua opinião, o que faz com que as pessoas se tornem ao mesmo tempo leitores e escritores é o gosto por certas formas de escrita:

\footnotetext{
...Veja bem... quando voce entra numa festa, sua tendência é procurar pessoas com quem você tenha afinidade... no mundo virtual é a mesma coisa. portanto, eu procuro - e acredito que sou lida - por gente que gosta do que eu gosto, que é literatura. literatura boa, de gente consagrada e a boa literatura de gente que ainda não é tão conhecido fora da internet.
}

Vai ainda mais longe, e aponta uma consequência bastante conhecida da existência de gostos em comum dentro e fora da rede: “...Na verdade, voce acaba fazendo parte de pequenas comunidades. há turmas, comunidades, que escrevem em outro formato".

Essa última colocação de Eros nos levou a investigar mais atentamente o quanto a ideia de que os blogs formam uma comunidade estava difundida entre os entrevistados. E, para nossa grande surpresa, dado que, quando começamos nossas investigações, os blogs ainda estavam muito vinculados ao individualismo da escrita de si, percebemos que os conceitos de comunidade, rede e network estavam presentes em muitos depoimentos (e quando não estavam explicitamente presentes, era evidente que as ações desses entrevistados mostravam ser fruto dessas concepções).
Uma comunidade virtual de escritores/leitores 
Comunidades de leitores e escritores existem há muito tempo. A disseminação da leitura no século XVIII, por exemplo, propiciou o surgimento de comunidades de leitura (a exemplo dos Book Clubs, Lesegesellschaften e Chambres de Lecture). Uma comunidade virtual de escritores e leitores na rede é, no entanto, algo radicalmente novo, cujo surgimento é propiciado pelo uso de recursos disponibilizados pelo hipertexto nos blogs. E nossos entrevistados parecem se dar conta disso por meio de seus conceitos de visitar, frequentar ou linkar outros blogs.

Eros novamente é quem aponta com clareza características singulares dos blogs que fornecem as bases para a formação dessas comunidades: "Quando eu escrevo no blog estou observando também como as pessoas reagem ao que eu escrevo, se gostam ou não, e colho este feed back através (dos comentários) conheço outros blogs que me visitam, alguns com conteúdos maravilhosos".

Em outras palavras, Eros escreve e observa a reação de seus leitores, que a levam para os blogs deles e para outros blogs. Sendo assim, os leitores que deixam comentários no blog de Eros também deixam o link para seus próprios blogs que ela visita. Quando gosta do que lê, Eros revela: “...Pego um pedaço e levo para o meu, indico, porque vale a pena".

Mota diz algo que também deixa clara a sua crença na formação de comunidades de blogs quando se refere a uma "rede de contatos onde o blog se insere..." (Mota, 27 anos, jornalista). E, ainda segundo Mota, a comunidade funciona tão bem que: "O que acontece algumas vezes é alguém mandar um link interessante - e o que é mais bacana, os mais chegados já dizem: 'isso aqui é a cara do seu blog!'”.
Os conceitos de comunidade, rede e network aparecem em muitas outras entrevistas. Dentre elas, destacam-se as de Maíra e Fox.

Maíra define sua entrada no mundo dos blogs como a entrada em uma comunidade de escritores e leitores que têm muito que conversar e trocar. Nessa comunidade - que, como em qualquer outra comunidade virtual, congrega pessoas que frequentemente não se conhecem no mundo real - interações de todos os tipos podem ocorrer. Maíra dá um exemplo disso ao revelar ter conseguido um namorado novo a partir do seu blog, um namorado que também é escritor de blogs e seu leitor:

\begin{abstract}
...A principal (razão para criar o blog)... foi encontrar muita gente que tinha os mesmos gostos que eu... percebi que eu andava com gente que tinha muito pouco a ver comigo... fiz muitos amigos... comecei a escrever mais, ler mais, ter prazer em conversar sobre isso com os amigos novos... e bem, me separei de um casamento/relacionamento de 8 anos em parte por causa dessas mudanças... e arrumei namorado novo também blogueiro. (Maíra, 27 anos, advogada)
\end{abstract}

Já Fox (bancário e webwriter) se refere ao blog como um espaço para encontrar pessoas, fazer amizades e fazer networking:

...Sou um cara muito tímido, que possui bem mais facilidade em se expressar escrevendo do que falando... Fiz várias amizades, não apenas virtuais como também in loco, graças ao meu blog. Também foi ótimo para o meu networking: já recebi algumas propostas de trabalho graças ao meu blog, principalmente depois que ele foi finalista dos prêmios iBest em 2003 e 2004. 


\section{Conclusão}

Nossos entrevistados parecem ter razões de sobra para não duvidar do fato de que fazem parte de uma comunidade virtual de escritores/leitores de blogs. E essa convicção é corroborada por outras fontes. Uma delas está relacionada a um acontecimento recente que gerou grande impacto no País inteiro.

Em 14 de setembro de 2007, a maioria dos grandes jornais - on-line e off-line - registrou a mesma notícia singular. Como uma forma de reação ao fato de que o Senador Renan Calheiros havia sido absolvido, pelo Senado Nacional, da acusação de ter tido despesas pessoais pagas pelo lobista de uma empreiteira, um grande número de escritores/leitores de blogs se uniu e utilizou uma técnica para associar a expressão vergonha nacional ao Senado brasileiro na popular ferramenta de busca Google. Abaixo podemos acompanhar como isso foi feito:

\section{Na web, site do Senado vira 'vergonha nacional'}

\begin{abstract}
A busca pela expressão vergonha nacional no site de procura Google mostra a página do Senado como a primeira ocorrência entre os resultados. Esse fenômeno aconteceu por causa de um movimento nacional liderado por blogs, como reação ao fato de o senador Renan Calheiros ter sido absolvido...

O feito foi conseguido através de uma técnica chamada Google Bombing. Blogs estão aplicando a técnica, disseminada de forma viral. (Dada) a forma como o site indexa dados na internet, quanto mais gente linkar o termo vergonha nacional ao site do Senado, mais acima na página de resultados ficará.
\end{abstract}

Se for colocado no Google o termo vergonha nacional e depois se clicar no botão Estou com sorte, o site do Senado abrirá direto (http://tecnologia.terra.com. br/interna/0,,Ol1908685-El4802,00.html, recuperado em 14 de setembro de 2007).

Além de confirmar a convicção dos escritores/ leitores por nós entrevistados de que fazem parte de uma comunidade virtual, esse episódio traz à tona uma pergunta cuja resposta também pode ser encontrada nos discursos dos entrevistados, quando analisados com cuidado. O que dá às comunidades virtuais de escritores/leitores de blogs esse poder de resistência e orientação/ formação da opinião pública?

Uma parte dessa resposta pôde ser obtida a partir da análise dos elementos que os entrevistados revelaram ser essenciais para que um blog chegue a fazer parte de uma comunidade virtual. Examinemos de perto esses elementos.

Para tentar inserir seu blog em uma rede de blogs, o autor tem que dar um primeiro passo, divulgá-lo. Esse passo pode ser dado fazendo uso dos recursos existentes no próprio blog ou na internet. O autor pode, por exemplo, recorrer aos diversos programas interativos (sincrônicos ou assincrônicos, como o MSN Messenger ou o e-mail) comumente utilizados pelos usuários da rede. Pode também lançar mão de outros expedientes, que fazem uso dos recursos disponíveis nos próprios blogs, como, por exemplo, aquele de incluir seu endereço em comentários deixados nos blogs de outros escritores/leitores, ao mesmo tempo mostrando a estes que eles são lidos e sutilmente convidando-os a visitar o novo blog (a expectativa de reciprocidade, como revelaram nossos entrevistados, é conhecida entre blogueiros). Em todos esses casos, o referido autor estará pressupondo a característica essencial de uma rede: a interconexão dos seus pontos. 
A divulgação, no entanto, é apenas o início do processo de inserção de um blog em uma rede de blogs. Tomando o universo dos blogs escritos por nossos entrevistados, pudemos detectar pelo menos três movimentos que parecem ser essenciais para dar ao escritor/ leitor a possibilidade de entrar de fato no universo dos blogs. Esses elementos são: (a) a constante atualização dos posts, (b) a inclusão de links para outros blogs e (c) as visitas feitas a outros blogs, neles deixando comentários como rastros ou deles incorporando trechos (visitas essas que são reciprocadas, deixando registros análogos). Enquanto o primeiro desses elementos aponta um aspecto central no mundo contemporâneo - o da necessidade de estar sempre atualizado, sempre sintonizado com o que está acontecendo -, os outros dois novamente apontam a fundamental interconexão.

A atualização e a interconexão, por sua vez, são os dois aspectos que geram a constante movimentação virtual que os entrevistados descrevem quando se referem às visitas recíprocas a partir dos links disponíveis nos blogs. São elas que dão aos blogs sua qualidade dinâmica. E é exatamente esse dinamismo interconectado e atualizado que dá às comunidades virtuais de escritores/ leitores de blogs o poder de resistência e de orientação/formação da opinião pública que pode ser observado em circunstâncias como a relatada acima.

Pensar que tudo isso foi tornado possível pelo surgimento das telas de computadores interconectados como suporte textual é dar razão a Chartier quando este afirma que a terceira revolução da escrita - a revolução digital - foi mais radical do que a invenção da imprensa; é também contestar a noção, ainda bastante difundida, de que o uso dos espaços interativos da internet revela, ou gera, alheamento da realidade cotidiana e descompromisso com esta. 


\section{Flavia Di Luccio}

Doutoranda do Departamento de Psicologia da Pontifícia Universidade Católica do Rio de Janeiro, Rio de Janeiro, RJ - Brasil. Pesquisadora do Núcleo de Estudos sobre Tecnologia e Subjetividade do Departamento de Psicologia da Pontifícia Universidade Católica do Rio de Janeiro.

E-mail : fluccio@uol.com.br

\section{Ana Maria Nicolaci-da-Costa}

PhD em Psicologia pela Universidade de Londres, Londre - Inglaterra. Professora do Departamento de Psicologia da Pontifícia Universidade Católica do Rio de Janeiro, Rio de Janeiro, RJ - Brasil. Coordenadora do Núcleo de Estudos sobre Tecnologia e Subjetividade do Departamento de Psicologia da Pontifícia Universidade Católica do Rio de Janeiro.

E-mail: anicol@puc-rio.br

\section{Endereço para envio de correspondência:}

Departamento de Psicologia da PUC-Rio. Rua Marquês de São Vicente, 225 - Gávea - Rio de Janeiro, RJ - Brasil - CEP: 22543-900.

Recebido 11/2/2009, Aprovado 10/8/2009.

\section{Referências}

Bertaux, D. (1980). L'approche biographique: sa validité méthodologique, ses potentialités. Cahiers Internationaux de Sociologie, LXIX, 197-225.

Chartier, R. (1998). A ordem dos livros: leitores, autores e bibliotecas na Europa entre os séculos XVI e XVIII (2a ed.). Brasília, DF: Ed. Universidade de Brasília.

Chartier, R. (1999). A aventura do livro: do leitor ao navegador. São Paulo: Ed. UNESP.

Chartier, R. (2002). Os desafios da escrita. São Paulo: Ed. UNESP.

Chartier, R. (2003). Formas e sentido. Cultura escrita: entre distinção e apropriação. Campinas, SP: Mercado de Letra \& Associação de Leitura do Brasil.

Di Luccio, F. (2005). As múltiplas faces dos blogs: um estudo sobre as relações entre escritores, leitores e textos. Dissertação de Mestrado, Departamento de Psicologia, Pontifícia Universidade Católica do Rio de Janeiro, Rio de Janeiro.

Komesu, F. C. (2005). Blogs e as práticas de escrita sobre si na internet. In L. A. Marcuschi \& A. C. Xavier (Orgs.), Hipertexto e gêneros digitais (pp. 110-119). Rio de Janeiro: Lucerna.

Lemos, A. L. M. (2002) A arte da vida. Webcams e diários pessoais na internet. Revista Comunicação e Artes: a Cultura das Redes, 305-319. Anais do Congresso ICNC 2001. Lisboa: Relógio d'Água.

Marcuschi, L. A., \& Xavier, A. C. (Orgs.) (2005). Hipertexto e gêneros digitais. Rio de Janeiro: Lucerna.

Nicolaci-da-Costa, A. M. (2006). Cabeças digitais: o cotidiano na era da informação. Rio de Janeiro: Editora PUC-Rio / Edições Loyola.

Nicolaci-da-Costa, A. M. (2007). O campo da pesquisa qualitativa e o método de explicitação do discurso subjacente (MEDS). Psicologia: Reflexão e Crítica, 20(1), 65-73.
Nicolaci-da-Costa, A. M., Romão-Dias, D., \& Di Luccio, F. (2009). O uso de entrevistas on-line no método de explicitação do discurso subjacente (MEDS). Psicologia: Reflexão e Crítica, 22, 36-43.

Prange, A. P. L. (2002). Da literatura aos blogs: um passeio pelo território da escrita de si. Dissertação de Mestrado, Departamento de Psicologia, Pontifícia Universidade Católica do Rio de Janeiro, Rio de Janeiro.

Recuero, R. C. (2003a). Warblogs: os weblogs, o jornalismo online e a guerra no Iraque. In Anais do XXVI Intercom-Sociedade Brasileira de Estudos Interdisciplinares da Comunicação, Belo Horizonte. Recuperado em 15 de março de 2008, de http:// pontomidia.com.br/raquel/warblogs.pdf.

Recuero, R. C. (2003b). Weblogs, webrings e comunidades virtuais. In 404notFound, 1(31), 1-15.

Schittine, D. (2004). Blog: comunicação e escrita íntima na internet. Rio de Janeiro: Civilização Brasileira.

Seidman, I. (1998). Interviewing as qualitative research: A guide for researchers in education and the social sciences. New York: Teachers College Press.

Silva, J. A. B. (2003). Weblogs: múltiplas utilizações e um conceito. In Anais do XXVI Intercom - Sociedade Brasileira de Estudos Interdisciplinares da Comunicação. Belo Horizonte. Recuperado em 15 de maio de 2008, de http://homer.nuted. edu.ufrgs.br/ObjetosPEAD2006/obj_blog/2003_NP08_silva. pdf 